Egyptian

Orthodontic Journal

\title{
EFFECT OF DIFFERENT 4 TOOTH SURFACE CONDITIONING TECHNIQUES ON SHEAR BOND STRENGTH OF ORTHODONTIC BRACKETS
}

\author{
Ahmed R. ElKalza' Dawlat Mostafa ${ }^{2}$
}

ABSTRACT:

Background: The aim of this study was to test, in vivo, the effect of using warm air for drying the tooth surface after conditioning, on the shear bond strength of orthodontic brackets. This shear bond strength was also compared to the shear bond strength of brackets after different tooth surface conditioning techniques with compressed air from 3-way syringe for drying etched enamel. Methods: eighty sound premolar teeth were divided into four groups (20 into each group). According to the methods used, brackets (mini 2000) were bonded after enamel preparation with acid etch (control), pumice prophylaxis+acid etch, pumice+sandblasting 50 microns +acid etch, pumice+sandblasting+acid etch+warm air. The teeth were mounted in metallic mold using a mounting jig to align their labial surfaces with the bonded brackets to be parallel to the applied force during the shear bond strength testing. Also after debonding, the amount of resin remaining on each tooth was evaluated. Results: there was a statistically significant difference among the four groups increased with the following sequence; group $B$ showed the significantly lowest shear bond strength values, then the control group, followed by group $C$ and finally group $D$ showed the significantly highest values. Adhesive remnant index (ARI) evaluation indicated higher frequency in group $\mathcal{A}, C$ and $\mathcal{D}$,

1- Lecturer, Department of Orthodontics, Faculty of Dentistry, Alexandria University. Egypt 2- Lecturer. Department of Biomaterials. Faculty of Dentistry. Alexandria University. Egypt 
Egyptian

Orthodontic Journal

if compared to group $B$. Conclusion: complete enamel preparation with pumice prophylaxis, followed by sand6lasting, acid etch and warm air drying significantly improved shear bond strength.

Key Words: Acid etch, Pumice, sandblasting, warm air, shear bond strength, Adhesive remnant index.

\section{INTRODUCTION}

Buonocore introduced the use of phosphoric acid in dentistry in 1955, and it became applicable to maintain a strong bond of composite to enamel. It is commonly proposed that to obtain good bond strength and minimal enamel loss, enamel should be etched by phosphoric acid 35 to $45 \%$ for 15 to $60 \mathrm{sec}^{(1,2,3)}$

The ideal time for etching enamel has been shown to be $15 \mathrm{sec}$. In the orthodontic field, this technology has resulted in significant treatment including esthetics and appliance hygiene, decreased soft tissue irritation and less possibility of enamel decalcification. . $^{(4,5,6,7)}$

Reynolds and Van Fraunhofer mentioned that adequate clinical bond strength in orthodontic range is from 5.9 to $7.9 \mathrm{Mpa}$. Direct bonding of orthodontic brackets was popular since 1970s, and thorough pumice prophylaxis followed by enamel etching has been recommended as a routine procedure for achieving a strong enamel resin bond. Miura et al mentioned that prophylactic cleaning is necessary for improved bond strength in $1973 .^{(10,11)}$

Previous studies showed that the use of pumice prior to etching is not important for successful bonding with conventional acid etch system. Lindauer et al found no difference regarding the use of pumice prophylaxis, when tested the effect of pumice prophylaxis on bond strength of orthodontic brackets in vivo and in vitro. Borg in 1995 as well as Ireland and Sherrif in 2002 mentioned that there was no effect on in-vivo bond failure rates when using pumice prophylaxis before conventional etching with composite for direct bonding. ${ }^{(12,13,14)}$ 
Egyptian

Orthodontic Journal

Air abrasive technique (sandblasting) is another method of enamel pretreatment that has been mentioned in the literature. Sandblasting makes use of a high stream of aluminium oxide particles (50-90 Um), propelled by air pressure. Some studies shown that sandblasting technique results in enamel surface changes. ${ }^{(15,16)}$

Sandblasting is based on the law of kinetic energy, which states that the harder the substance, the faster the cutting speed; the softer the substance, the slower the cutting speed. This effect was a disadvantage in late $1950 \mathrm{~s}$, but nowdays, it is an advantage in terms of protecting the oral soft tissue. ${ }^{(17,18)}$

The use of sandblasting technique in orthodontics and other fields of dentistry may be feasible for preparing teeth before bonding for increased bond strength. ${ }^{(19)}$

Previous methods have been used to dry the tooth surface after etching by a blotting paper, compressed air, warm air tooth dryer. ${ }^{(20)}$

Batchelder et al evaluated the effect of various sources of drying air, and found that specimens dried with warm air showed higher shear bond strength than those dried with room temperature compressed air. The source of warm air was a $1.750 \mathrm{~W}$ commercial heat gun, and the temperature of the air measured near the enamel surface was $50^{\circ} \mathrm{c}{ }^{(21)}$

Galan et al also reported significantly increased shear bond strength with the use of warm air, but did not mention the source and temperature of the air. However, no study has been done to assess the effectiveness of warm air to dry etched enamel, while bonding orthodontic brackets. ${ }^{(23)}$

The purpose of this study was to test, in vivo, the effect of using warm air for drying the tooth surface after conditioning, on the shear bond strength of orthodontic brackets. This shear bond strength was also compared to the shear bond strength of brackets after different tooth surface conditioning techniques with compressed air from 3-way syringe for drying etched enamel. 
Egyptian

Orthodontic Journal

\section{MATERIALS \& METHODS}

Sample size:

Eighty sound (maxillary and mandibular, first and second) premolar teeth extracted from orthodontic patients were stored in distilled water and randomly divided into 4 groups of 20 each. The teeth were selected by the following criteria: intact buccal enamel, not subjected to any pretreatment chemical agents, such as hydrogen peroxide, and no caries or cracks even resulted from the extraction forceps.

Sample size was calculated based on a previous study, by using Med Calc statistical software.

Assuming area under ROC to be 0.80 , an alpha of 0.05 and power of study $90.0 \%$. a minimum sample size required was 20 sample in each group will be required

Group A (Acid-etch)

Buccal surfaces of the premolar teeth were acid etched with $37 \%$ phosphoric acid gel (Reliance orthodontic products, Inc, USA) for 15 seconds, thoroughly rinsed with water from a 3-in-1 syringe for 30 seconds, and then dried with an oil-free source for 20 seconds.

Group B (Pumice and acid-etch)

The buccal surfaces were pumiced for 10 seconds with a fluoridefree fine pumice slurry, acid etched with $37 \%$ phosphoric acid gel for 15 seconds, thoroughly rinsed with water from a 3-in-1 syringe for 30 seconds, and then dried with an oil-free source for 20 seconds

Group C (Pumice, sandblasting and acid-etch)

The buccal surfaces were pumiced for 10 seconds, then sandblasting was done with 50 microns aluminium oxide in a microetcher (Danville Engineering Inc, Danville, Calif) at 80 psi for 5 seconds through a nozzle distance of $10 \mathrm{~mm}$ at 45 degree angle. After sandblasting the teeth, surfaces were cleaned with compressed air to remove sandblasting 
powder. Then etching was carried out with $37 \%$ phosphoric acid gel for 15 seconds, thoroughly rinsed then dried for 20 seconds.

Group D (Pumice, sandblasting, acid-etch and warm air drying)

After the buccal surfaces were pumiced, sandblasted and acid etched and rinsing, the enamel surface was dried with warm air using a professional Nola tooth drier (Great Lakes orthodontics, 1td) for 10 seconds.

Eighty premolar brackets (Ormco, mini 2000) were used for this study. A thin layer of solo bond (Ormco) was applied to the enamel and light cured for 10 seconds. Brackets were bonded onto the center of the buccal surface of teeth with green gloo (Ormco), a light cured composite adhesive. Before curing, the excess resin material was removed with a probe around the bracket without disturbing bracket position. The adhesive was light cured for a total of 40 seconds, following manufacturer's instructions.

\section{Shear Bond Strength Test}

The premolars were mounted with cold cured acrylic resin in metallic mold using a mounting jig to align their labial surfaces with the bonded brackets to be parallel to the applied force during the shear bond strength testing. The brackets were shear tested to failure using an Instron universal testing machine (CEDM-4, Comten Industries, USA) to produce a shear force at the tooth-brackets interface through the application of an occlusogingival load with a cross head speed of $1 \mathrm{~mm} / \mathrm{min}$. The shear force producing failure was recorded in Newton for all specimens.

\section{Adhesive Remnant Index}

After debonding, a stereomicroscope (Olympus, Japan) was used to examine the teeth and brackets under an eye piece magnification of [11X] to evaluate the amount of resin remaining on each tooth. The adhesive remnant index (ARI) was used to describe the quantity of resin remaining on the tooth surfaces ${ }^{(24)}$. The ARI score has a range between 0 and 3 as follows: 
Score 0: No adhesive left on the tooth

Score 1: Less than $1 / 2$ of adhesive left on the tooth

Score 2: More than $1 / 2$ of adhesive left on the tooth

Score 3: All adhesive left on the tooth

\section{Statistical analysis of the data}

Data were fed to the computer and analyzed using IBM SPSS software package version 20.0. Qualitative data were described using number and percent. Quantitative data were described using range (minimum and maximum), mean, standard deviation and median. Significance of the obtained results was judged at the 5\% level. The test was used in comparison between more than two groups, ANOVA test, followed by post hoc test to determine the significant between each two groups. Chi square test was used categorical variables, to compare between different groups.

\section{RESULTS}

The descriptive statistics comparing the shear bond strength of the four groups are given in Table 1, Fig 1. The results of the shear bond strength for the four groups using ANOVA test, followed by post hoc test indicated that, the shear bond strength of the control group $A$ $($ mean $=176.6-188.2 \mathrm{~N})$, group $\mathrm{B}(\mathrm{P}=0.012$; mean $=156.5-168 \mathrm{~N})$ was significantly lower than the control, while the other two groups $\mathrm{C}$ $(\mathrm{P}=0.042$; mean $=189.7-198.8 \mathrm{~N})$ and $\mathrm{D}(\mathrm{P}=0.001$; mean $=210.1-253.2 \mathrm{~N})$ revealed significantly higher values. There was a statistically significant difference among the four groups increased with the following sequence; group B showed the significantly lowest shear bond strength values, then the control group, followed by group $\mathrm{C}$ and finally group $\mathrm{D}$ that showed the significantly highest values. 


\section{Egyptian}

Orthodontic Journal

Table (1): Comparison between the four studied groups regarding the shear bond strength (Newton).

\begin{tabular}{|c|c|c|c|c|}
\hline & $\begin{array}{c}\text { Group A } \\
\text { Control }\end{array}$ & Group B & Group C & Group D \\
\hline Range & & & & \\
\hline Mean & 176.6-188.2 & $156.5-168$ & 189.7-198.8 & $210.1-253.2$ \\
\hline S.D. & $182.34 \pm 3.92$ & $161.72 \pm 3.47$ & $194.00 \pm 3.60$ & $229.28 \pm 12.63$ \\
\hline $\mathrm{F}$ & \multirow{2}{*}{\multicolumn{4}{|c|}{$\begin{array}{c}22.6 \\
0.001 *\end{array}$}} \\
\hline $\mathrm{P}$ & & & & \\
\hline P1 & & $0.012 *$ & $0.042 *$ & $0.001 *$ \\
\hline P2 & & & $0.001 *$ & $0.0001 *$ \\
\hline P3 & & & & $0.017 *$ \\
\hline
\end{tabular}

$P 1$ comparison between control and other groups

$P 2$ comparison between group $B$ and both $C$ and $D$

$P 3$ comparison between group $C$ and $D$

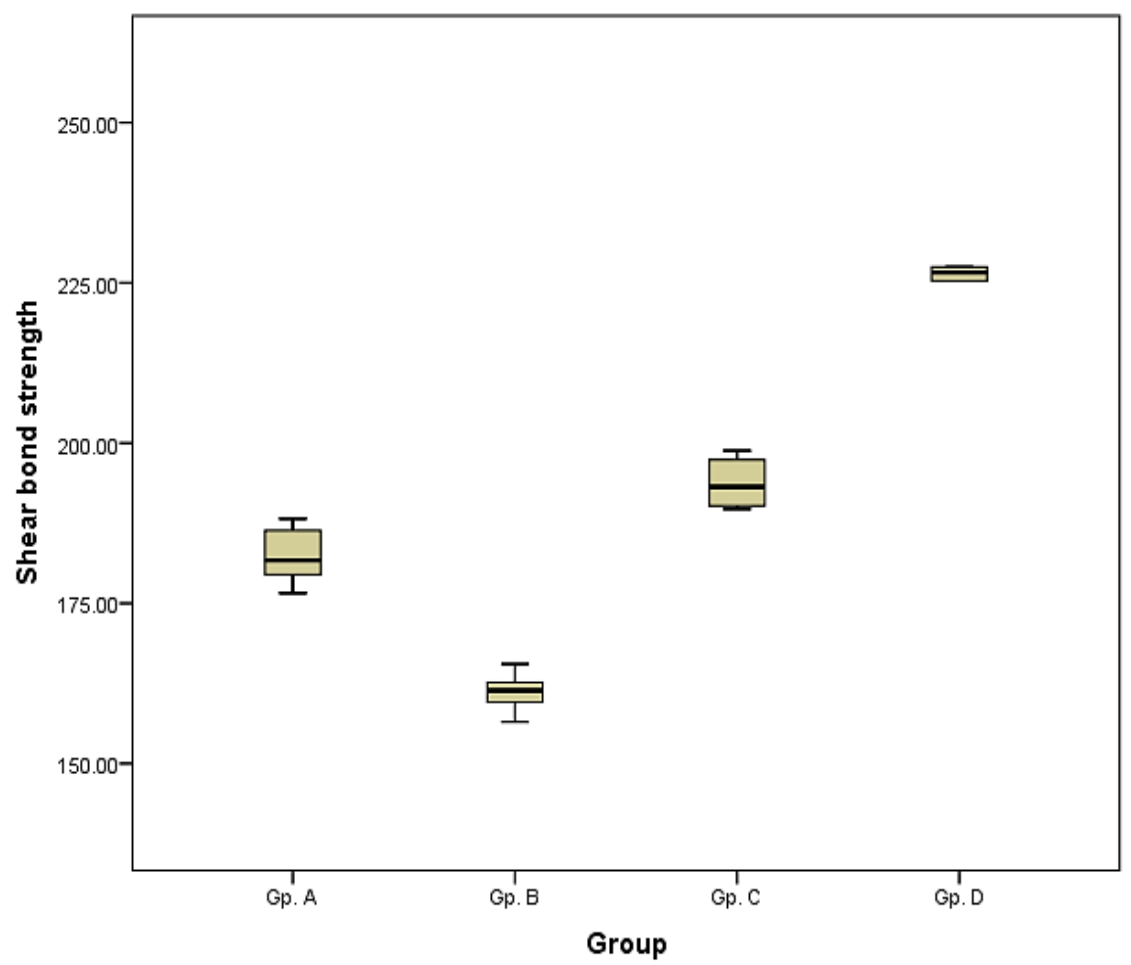

Volume 51 - June 2017 


\section{Egyptian}

Orthodontic Journal
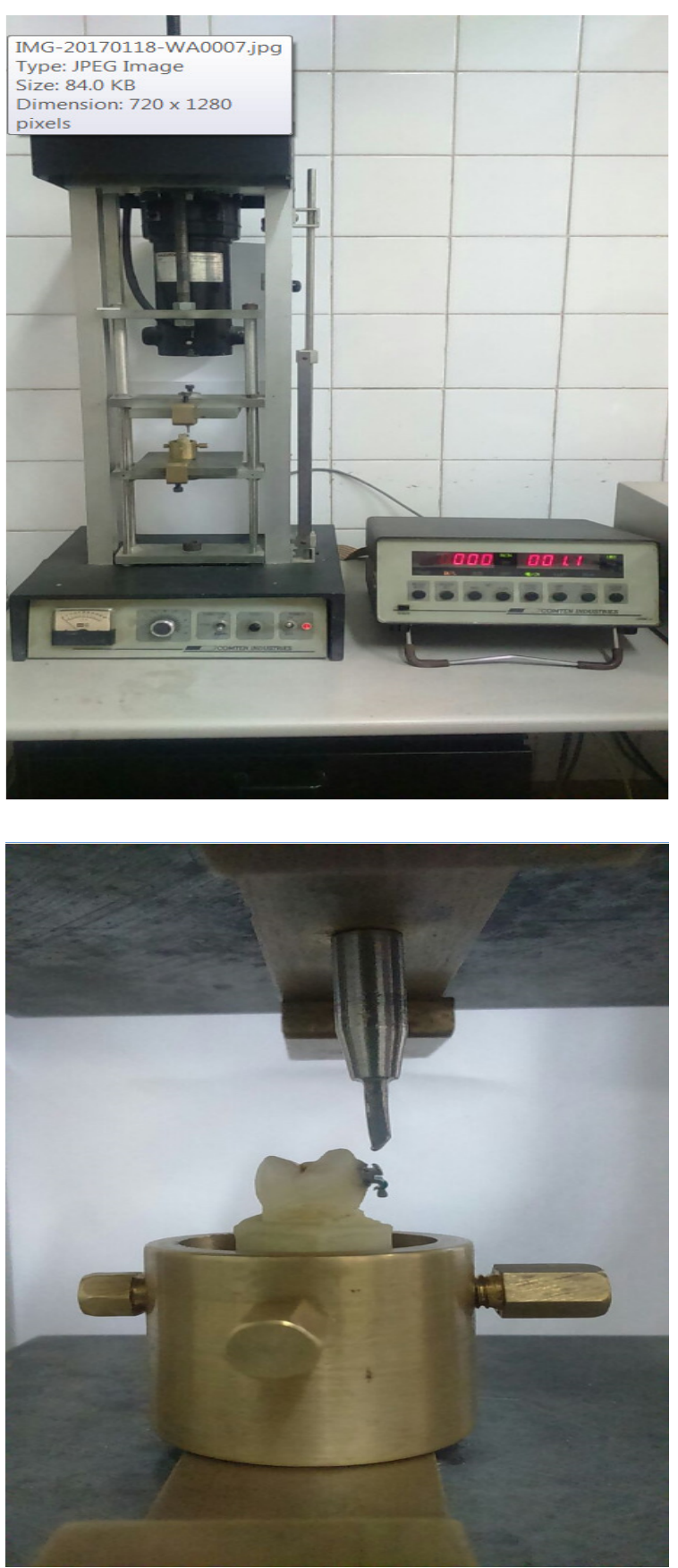

Volume 51 - June 2017 


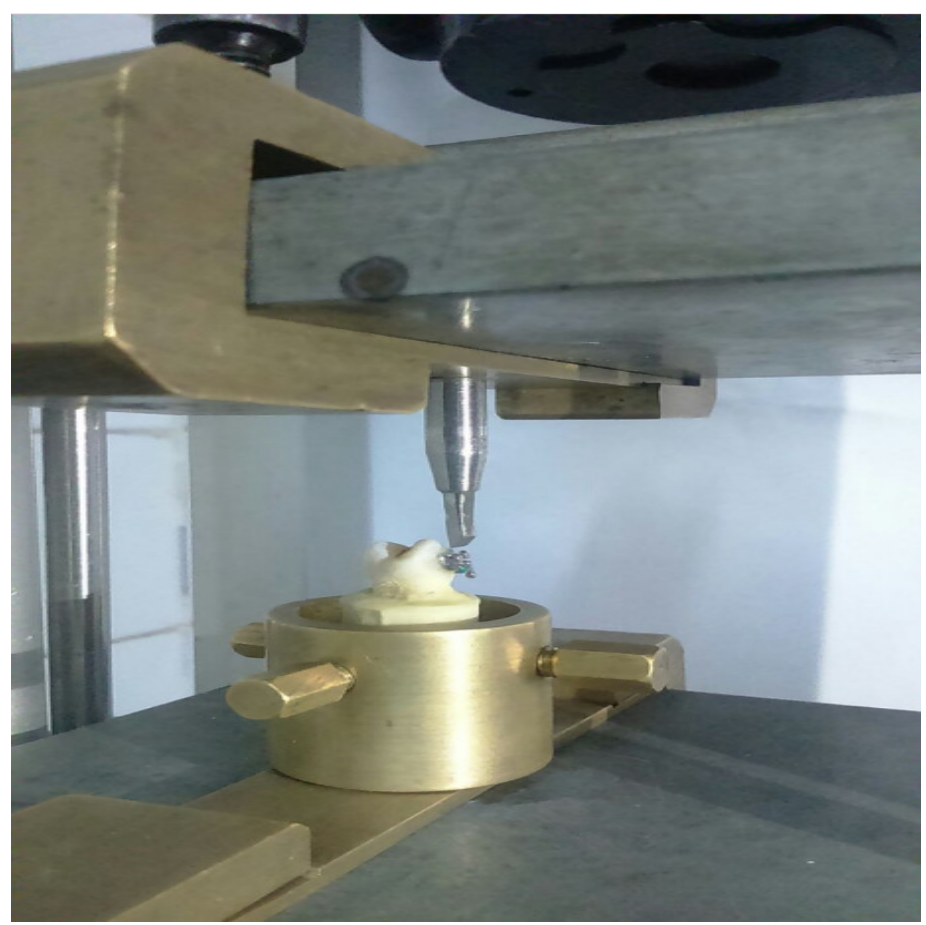

The ARI scores for the four groups tested are listed in Table 2. The results of the chi-square comparisons for ARI indicated that, there was a statistically significant difference between group B and the other three tested groups $(\mathrm{P}=0.001)$, while there was no statistically significant difference among the control group $\mathrm{A}$, group $\mathrm{C}(\mathrm{P}=0.108)$ and group $\mathrm{D}$ $(\mathrm{P}=0.089)$. There was a higher frequency of ARI scores of [3] in the control group A ( 8 specimens), group C ( 9 specimens) and group D (10 specimens), which indicated that more composite remained on the teeth of these three tested groups, if compared with group B that recorded no specimens in score [3]. 
Egyptian

Orthodontic Journal

Table (2): Comparison between the four studied groups regarding Adhesive Remnant Index score.

\begin{tabular}{|c|c|c|c|c|c|c|c|c|}
\hline \multirow[t]{2}{*}{ Score } & \multicolumn{2}{|c|}{$\begin{array}{c}\text { Group A } \\
\text { Control }\end{array}$} & \multicolumn{2}{|c|}{ Group B } & \multicolumn{2}{|c|}{ Group C } & \multicolumn{2}{|c|}{ Group D } \\
\hline & No. & $\%$ & No. & $\%$ & No. & $\%$ & No. & $\%$ \\
\hline 0 & 4 & 20 & 12 & 60 & 3 & 15 & 2 & 10 \\
\hline 1 & 3 & 15 & 3 & 15 & 2 & 10 & 2 & 10 \\
\hline 2 & 5 & 25 & 5 & 25 & 6 & 30 & 6 & 30 \\
\hline 3 & 8 & 40 & 0 & 0 & 9 & 45 & 10 & 50 \\
\hline $\begin{array}{l}X^{2} \\
P\end{array}$ & \multicolumn{7}{|c|}{29.8} & \\
\hline $\mathrm{P} 1$ & & & \multicolumn{2}{|c|}{$0.001 *$} & \multicolumn{2}{|c|}{0.108} & \multicolumn{2}{|c|}{0.089} \\
\hline $\mathrm{P} 2$ & & & & & \multicolumn{2}{|c|}{$0.001^{*}$} & \multicolumn{2}{|c|}{$0.001 *$} \\
\hline P3 & & & & & & & \multicolumn{2}{|c|}{0.074} \\
\hline
\end{tabular}

$\mathrm{P} 1$ comparison between control and other groups

$\mathrm{P} 2$ comparison between group $\mathrm{B}$ and both $\mathrm{C}$ and $\mathrm{D}$

$\mathrm{P} 3$ comparison between group $\mathrm{C}$ and $\mathrm{D}$

\section{DISCUSSION}

Generally, There was a clear difference among the four groups with group B showing the lowest shear bond strength values and increased through group $\mathrm{A}$, followed by group $\mathrm{C}$ and group $\mathrm{D}$ subsequently.

Lindauer et al, found that pumice prophylaxis before preparation of the tooth surface for bonding does not offer any advantage and that pumice prophylaxis does not affect the bonding procedure quality. ${ }^{(12)}$

Lill et al, mentioned that the orthodontic bond failure rates in vivo for a self etching primer system was five times greater when pumice pretreatment was performed. ${ }^{(25)}$

Conay et al, found that sandblasting with aluminium oxide particles followed by acid etching had higher bond strength than sandblasting or conventional acid etching done alone. ${ }^{(19)}$ 
Egyptian

Orthodontic Journal

Goyal et al, mentioned that moisture weakens the bond strength of composite to teeth. Warm air dryer results in higher shear bond strength compared with conventional air syringe. This difference may be due to residual tooth heat that facilitated the polymerization of the bonding agent and/or composite resin. ${ }^{(23)}$

Another possible reason could be due to the effect of warm air on the patient's breath. Warm air could dry out the humidity from the patient's exhaled air, thus preventing possible moisture contamination of the bonding agent and / or composite resin.

In the present study, group $\mathrm{A}, \mathrm{C}$ and $\mathrm{D}$ showed more composite remained on the teeth, while group $\mathrm{B}$ recorded no adhesive remnant.

Goyal et al, observed that acid etching followed by warm air dryer resulted in strong bond between the adhesive and the tooth surface, but also recommended the need to remove the remnant adhesive which remains on the tooth surface after debonding the brackets. ${ }^{(23)}$

\section{CONCLUSION}

It can be concluded from the present study that complete enamel preparation including pumice prophylaxis, followed by sandblasting, etching and warm air dryer shows significantly improved shear bond strength.

On the other hand, the three groups showing significant high bond strength, leave remnant adhesive which needs to be removed from tooth surface and carry the risk of removing some healthy tooth structure along with additional chair time.

\section{REFERENCES}

1. Buonocore MG. A simple method of increasing the adhesion of acrylic filling materials to enamel surfaces. J Dent Res 1955; 34:849-53.

2. Wang WN, Yeh CL, Fang BD, Sun KT, Arvystas MG. Effect of H3PO4 concentration on bond strength. Angle Orthod 1994; 64:377-82. 
3. Barkmeier WW, Gwinnett AJ, Schaffer SE. Effects of enamel etching time on bond strength and morphology. J Clin Orthod 1985; 19:36-8.

4. Kocadereli Iken, Ciger S, Tuncel M, Ilgi S. The tensile bond strength of young permanent teeth with shorter etching times. Turk J Orthod $1995 ; 8: 242-6$.

5. Wang WW, Lu TL. Bond strength with various etching times on young permanent teeth. Am J Orthod Dentofacial Orthop 1991; 100:72-9.

6. Sheen DH, Wang WN, Tang TH. Bond strength of younger and older permanent teeth with various etching times. Angle Orthod 1993; 63:225-30.

7. Zachrisson B. Cause and prevention of injuries to teeth and supporting structures during orthodontic treatment. Am J Orthod 1976; 69:385-300.

8. Newman G. Epoxy adhesive for orthodontic attachments: progress report. Am J Orthod 1965; 51:901-2.

9. Reynolds IR, Von Fraunhofer JA. Direct bonding of orthodontic attachments to teeth: the relation of adhesive bond strength to mesh size. Br J Orthod 1976; 3:01-5.

10. Chow LC, Brown WE. Phosphoric acid conditioning of teeth for pit and fissure sealants. J Dent Res 1973; 52:1158.

11. Miura F, Nakagawa K, Ishizaki A. Scanning electron microscopic studies on the direct bonding system. Bull Tokyo Med Dent Univ $1973 ; 20: 245-60$.

12. Lindauer SJ, Browning H, Shroff B, Marshall F, Anderson R. Effect of prophylaxis on the bond strength of orthodontic brackets. Am J Orthod Dentofacial Orthop 1997; 111:599-605. 
13. Barry GR. A clinical investigation of the effects of omission of pumice prophylaxis on band and bond failure. Br J Orthod 1995; 22:245-8.

14. Ireland AJ, Sherriff M. The effect of pumicing on the in vivo use of a resin modified glass poly (alkenoate) cement and a conventional no-mix composite for bonding orthodontic brackets. J Orthod 2002; 29:217-20.

15. Katora ME, Jubach T, Polimus MM. Airabrasive etching of the enamel surface. Quint Int 1981; 9:967-8.

16. Goldstein RE, Parkins FM. Using air-abrasive technology to diagnose and restore pit and fissure caries. J Am Dent Assoc 1995; 126:761-6.

17. Goldstein R, Parkins F. Air-abrasive technology: its new role in restorative dentistry. JADA 1994; 125:551-7.

18. Gerbo L, Barnes C, Leinfelder K. Applications of the air-powder polisher in clinical orthodontics. Am J Orthod Dentofacial Orthop 1993; 103:71-3.

19. Canay S, Kocadereli I, Akca E. The effect of enamel air abrasion on the retention of bonded metallic orthodontic brackets. Am J Orthod Dentofacial Orthop 2000; 117:15-19.

20. Cooley RL, Young JM, Train TE. Evaluation of an air operated tooth dryer. Quintessence Int 1998; 20:577-88.

21. Batchelder KF, Richter RS, Vaidyanathan TK. Clinical factors affecting the strength of composite resin to enamel bonds. J Am Dent Assoc. 1987 Feb; 114(2):203-5.

22. Galan D, Williams PT, Kasloff Z. Effect of warm-air drying and spreading on resin bonding. Am J Dent. 1991 Dec;4(6):277-80. 
23. Amit Goyal, Shivalinga BM, Jyothikiran H. Effect of drying the etched tooth surface with warm air on shear bond strength of metallic orthodontic brackets. Indian J Dent Sciences. 2012; 1(4):13-16.

24. Artun J, Bergland S. Clinical trials with crystal growth conditioning as an alternative to acid etch enamel treatment. Am J Orthod 1984; $85: 333-40$.

25. Lill DJ, Lindauer SJ, Tufekci E, Shroff B. Importance of pumice prophylaxis for bonding with self-etch primer. Am J Orthod Dentofacial Orthop 2008; 133:423-6. 